\title{
Supervised co-prescription of heroin to treatment-resistant heroin addicts is more effective than treatment with methadone alone
}

van den Brink W, Hendriks VM, Blanken P, et al. Medical prescription of heroin to treatment resistant heroin addicts: two randomised controlled trials. BMJ 2003;327:310.

Is supervised prescription of heroin successful in treating people addicted to heroin, who have not benefited from methadone maintenance treatment?

\section{METHODS}

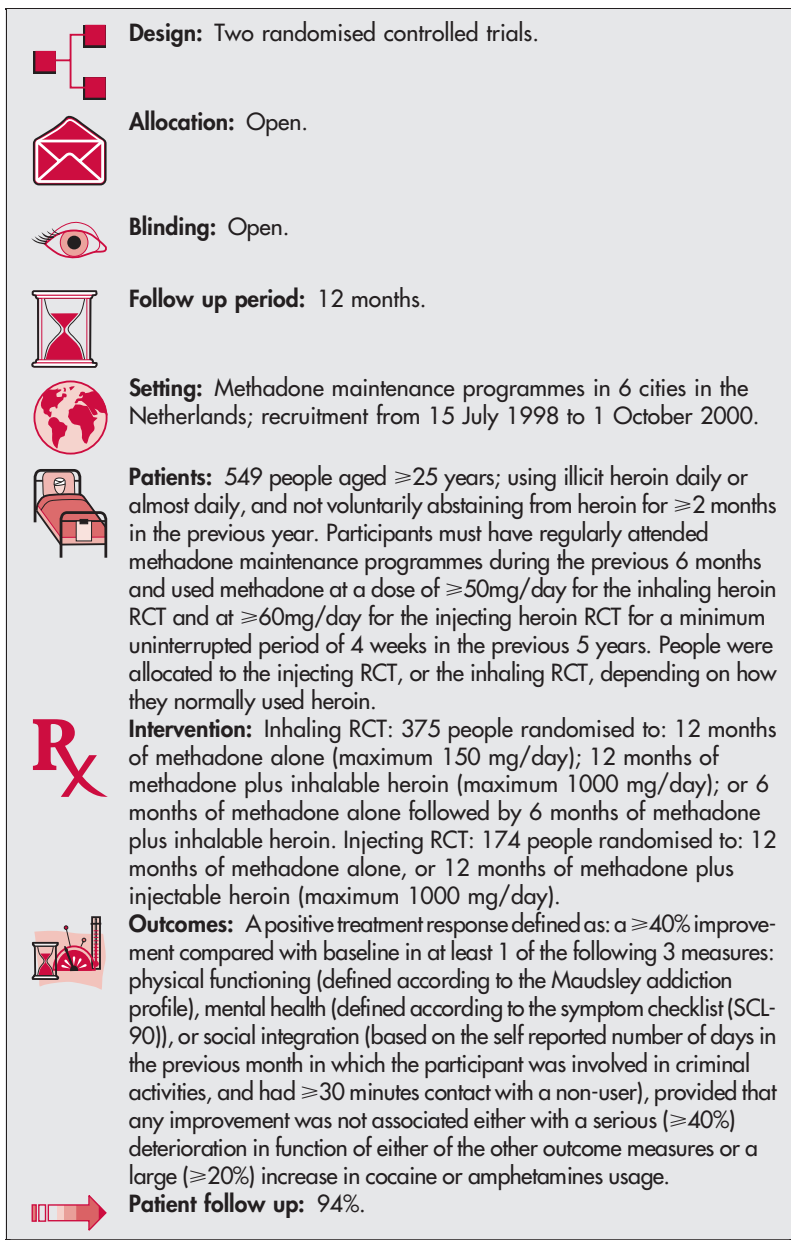

MAIN RESULTS

In both RCTs, treatment with methadone plus heroin produced more positive responses in at least one of the physical, mental, or social outcome measures compared with methadone alone (see table 1). CONCLUSIONS

Supervised co-prescription of heroin to treatment-resistant heroin addicts was more effective than treatment with methadone alone.

For correspondence: W van den Brink, Central Committee on the Treatmen ofHeroin Addicts, Stratenum, Utrecht, Netherlands; w.vandenbrink@amc.uva.nl Source of funding: The Netherlands Ministry of Health, Welfare and Sports.

\section{Commentary}

I eroin dependence is a major public health problem and has high social costs. Prescribing pharmaceutical heroin (diamorphine) to heroin addicts has been seen in some countries as a way of reducing the associated harms. The most common form of substitution drug for heroin dependence is methadone. However, despite, the benefits of oral methadone, ${ }^{1}$ there are individuals who appear not to want it nor benefit from it. It has been suggested, therefore, that pharmaceutical heroin should be prescribed to these individuals.

The evidence base for the effectiveness of prescribing heroin is small. Previous research includes four small scale studies conducted in the $\mathrm{UK}_{1}^{2-5}$ one large cohort study conducted in Switzerland, ${ }^{6}$ and one small randomised trial conducted in Geneva. ${ }^{7}$ While the results of these studies suggest that prescribing heroin is feasible, improves health, and reduces illicit drug use and crime, the lack of control groups limits interpretation. Only two studies used a randomised controlled design. Without suitable control groups, it is not known whether similar results might have been achieved with oral methadone or if the results are due to the additional psychosocial interventions, or both.

van den Brink and colleagues should be congratulated on using a scientifically rigorous design to examine the effectiveness of prescribing heroin. Furthermore, this is the first study of a non-injectable preparation of heroin and to use non-injecting drug users. They found that those receiving a co-prescription of heroin made significantly better improvements than those receiving methadone only.

These trials provide useful information, but, since the treatment context differs in other countries, it is unclear how far results from these trials are generalisable. Patient interest in receiving heroin will be influenced by the usual delivery of treatment (eg supervised consumption of prescription or dispensed daily for unsupervised consumption at home) and by the history, quality, accessibility, and availability of treatments in their particular country. Nicky Metrebian

Research Fellow, Dept Social Science \& Medicine, Imperial College London, UK

1 Ward J, Mattick RP, Hall W. The effectiveness of methadone maintenance treatment 2: HIV and infectious hepatitis. In: Ward J, Mattick RP, Hall W, eds. Methadone maintenance treatment and other opioid replacement therapies. Australia: Harwood Academic Publishers, 1998:59-74.

2 Metrebian N, Shanahan W, Wells B, et al. Feasibility of prescribing injectable heroin and methadone to opiate dependent drug users; associated health gains and harm reductions. Med J Aust 1998;168:596-600.

3 McCusker C, Davis M. Prescribing drug of choice to illicit heroin users; the experience of a UK community drug team. J Subst Abuse Treat 1996;13:521-31.

4 Hartnoll RL, Mitcheson MC, Battersby A, et al. Evaluation of heroin maintenance in controlled trial. Arch Gen Psychiatry 1980;37:877-84.

5 Stimson GV, Ogborne AC. Survey of addicts prescribed heroin at London clinics. Lancet 1970;30:1163-6.

6 Uctenhagen A, Dobler-Mikola A, Steffen T, et al. Prescription of narcotics for heroin addicts: main results of Swiss national cohort study. Volume 1: medical prescription of narcotics. Basel: Karger; 1999.

7 Perneger TV, Giner F, del Rio M, et al. Randomised trial of heroin maintenance programme for addicts who fail in conventional drug treatments. BMJ 1998;317:13-18.

\section{NOTE}

There were a number of methodological limitations that were identified by the authors, such as reliance on self reported outcome measures, and difference in settings between the treatment groups.

Table 1 Outcome measures in the inhaling and injecting RCT.

\begin{tabular}{|c|c|c|c|c|c|c|}
\hline & \multicolumn{3}{|l|}{ Inhaling } & \multicolumn{3}{|l|}{ Injecting } \\
\hline & $\begin{array}{l}\text { Methadone } \\
\text { alone }(n=139)\end{array}$ & $\begin{array}{l}\text { Methadone plus } \\
\text { heroin ( } n=117 \text { ) }\end{array}$ & ARR $(95 \% \mathrm{Cl})$ & $\begin{array}{l}\text { Methadone } \\
\text { alone ( } n=98)\end{array}$ & $\begin{array}{l}\text { Methadone plus } \\
\text { heroin }(n=76)\end{array}$ & ARR $(95 \% \mathrm{Cl})$ \\
\hline Completed 12 months treatment (\%) & $121(87)$ & $80(68)$ & $18.7(8.8$ to 28.6$)$ & $83(85)$ & 55 (72) & $12.3(0.2$ to 24.5$)$ \\
\hline Response rated ITT (\%) & $37(27)$ & $58(50)$ & $22.8(11.0$ to 34.6$)$ & $31(31)$ & $42(56)$ & $24.3(9.6$ to 39.0$)$ \\
\hline Sustained* response at 12 months (\%) & $6(4)$ & $26(22)$ & $17.9(9.7$ to 26.1$)$ & $11(12)$ & $19(25)$ & 13.1 (1.5 to 24.7$)$ \\
\hline
\end{tabular}

*Sustained responders were people who achieved a positive response before the 12 month assessment and remained responders throughout the trial. 